\title{
Correction to: Chromobox Homolog 4 is Correlated with Prognosis and Tumor Cell Growth in Hepatocellular Carcinoma
}

\author{
Boqing Wang, $\mathrm{MD}^{1,2}$, Jianjun Tang, $\mathrm{MD}, \mathrm{PhD}^{2}$, Dan Liao, $\mathrm{MD}^{2}$, Gang Wang, $\mathrm{MD}^{2}$, Meifang $\mathrm{Zhang}, \mathrm{MD}^{2}$, \\ Yi Sang, $\mathrm{PhD}^{2}$, Jingying Cao, $\mathrm{MD}^{2}$, Yuanzhong $\mathrm{Wu}, \mathrm{PhD}^{2}$, Ruhua Zhang, $\mathrm{MD}^{2}$, Shengping $\mathbf{~ L i , ~} \mathrm{MD}^{2}$, \\ Wei Ding, MD ${ }^{1}$, Guoqing Zhang, $\mathrm{MD}^{1}$, and Tiebang Kang, $\mathbf{P h D}^{2}$ \\ ${ }^{1}$ Department of Hepatopancreatobiliary Surgery, Affiliated Tumor Hospital, Xinjiang Medical University, Ürümqi, \\ Xinjiang, China; ${ }^{2}$ State Key Laboratory of Oncology in South China, Sun Yat-Sen University Cancer Center, Guangzhou, \\ Guangdong, China
}

CORRECTION TO: ANN SURG ONCOL (2013) 20:S684-S692

HTTPS://DOI.ORG/10.1245/S10434-013-3171-7

The image for siCBX4-2 was misplaced with the same image for siCBX4-1 in Fig. 3d. The corrected figure is provided here. This change does not affect the validity of the data and conclusions drawn, or any other aspects of this paper.

The original article can be found online at https://doi.org/10.1245/ s10434-013-3171-7.

(C) Society of Surgical Oncology 2021

Published Online: 2 July 2021

G. Zhang, MD

e-mail: zgqprofessor@sina.com

T. Kang, $\mathrm{PhD}$

e-mail: kangtb@mail.sysu.edu.cn 
FIG. 3 a, b Silencing CBX4 inhibits HCC cell growth. The viability of the 2 cells,

BEL7402 (a) and QGY-7703

(b), was examined by MTT assay at different time points as indicated. The results were expressed as mean $\pm \mathrm{SD}$ of 3 independent experiments, $* P<$ $0.05, * * P<0.01$, by independent Student's $t$-test. c, d Silencing CBX4 delays G1/S transition in HCC cells. Cells were synchronized at G1/S boundary by double thymidine block and released, and the cell cycle profiles were measured by FACS. Endogenous CBX4 was silenced in BEL7402 (c) and QGY-7703 (d) cells, and the cell cycle profiles were measured by FACS at 12-h and 6-h time points after release from G1/S boundary,

respectively. e, f Summary of independent FACS tests for the BEL7402 (e) and QGY-7703 (f) cell lines, $* P<0.05$, $* * P<$ 0.01. CBX4 siRNAs were transiently transfected into BEL-7402 cells; 6 h later, medium was replaced with fresh serum-free media and the cells were starved for another $48 \mathrm{~h}$, followed by $10 \%$ FBS medium stimulated for $12 \mathrm{~h}$. g,

h Western blot test (g) and qRTPCR (h) showing changes of downstream genes after knockdown of CBX4 (a)

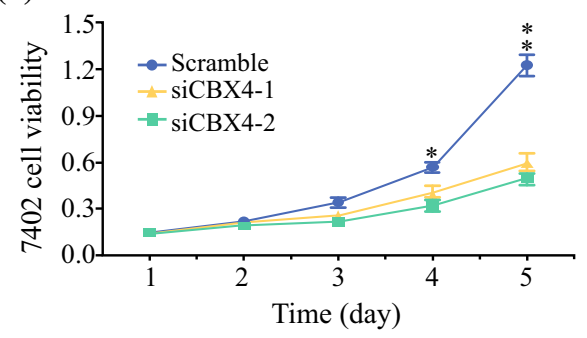

(c)

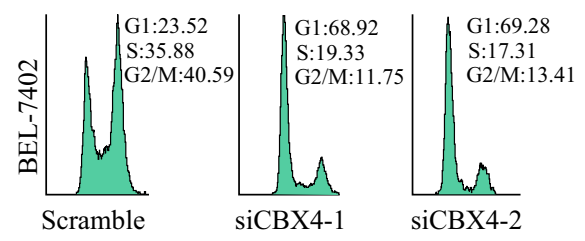

(e)

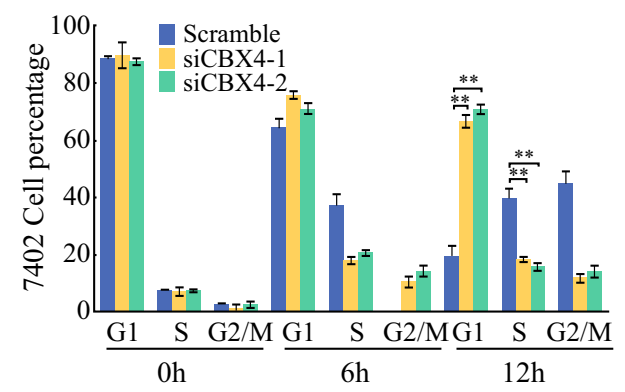

(g)

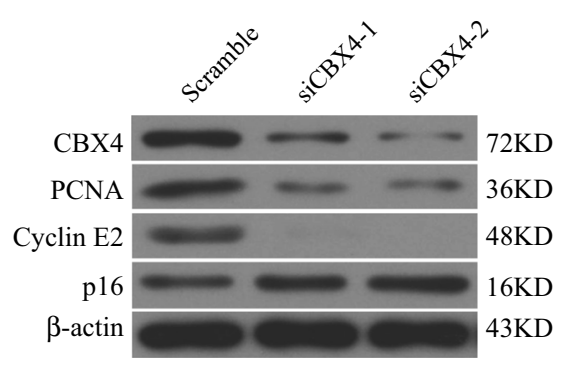

(b)

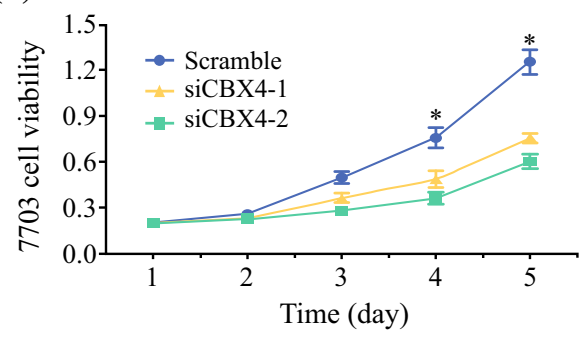

(d)

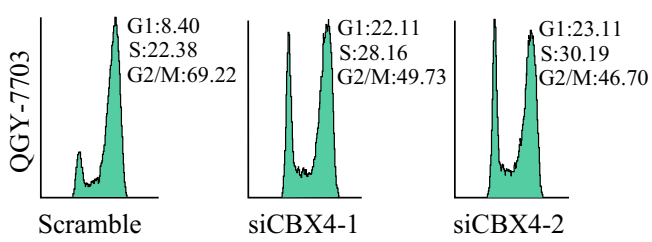

(f)

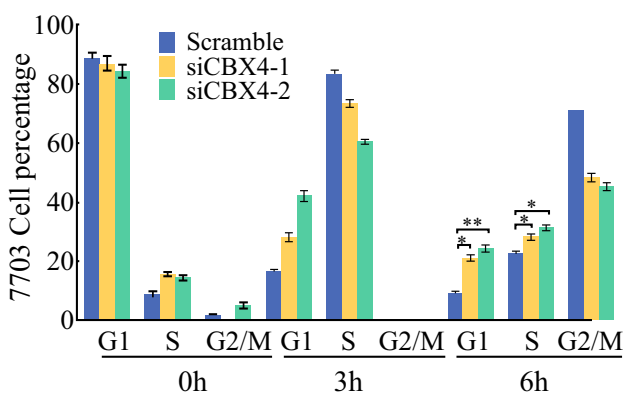

(h)

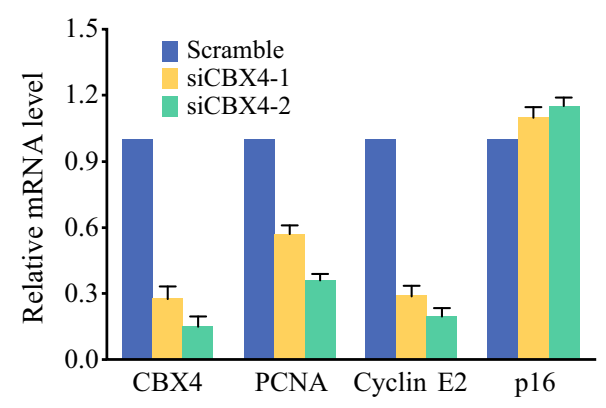

Publisher's Note Springer Nature remains neutral with regard to jurisdictional claims in published maps and institutional affiliations. 